\title{
Online Supplement: Ideological Preferences and Evolution of the Religious Cleavage in Chile, 1998-2014
}

Matías Andrés Bargsted and Nicolás De la Cerda

In this document, we present further details about measurement and the data analysis shown in the main body of the article. Section A provides information about the correlation between respondents' ideological and electoral preferences. Section B details the evolution of correlations between respondents' ideological preferences and several other more specific political opinions. Lastly, section C provides summary statistics of all variables included in the quantitative analysis of CEP survey data.

\section{A. Correlations between Ideological and Electoral Preferences.}

In this section, we show empirical information that confirms that respondents' ideological and electoral preferences are closely related. This is an important result given that empirical studies analyzing the evolution of social cleavages normally employ vote intention or recall as the dependent variable (though see Valenzuela et al, 2007; Harbers et al., 2013, and Bargsted and Somma 2016 for some exceptions). This analysis also relies on CEP surveys. These have most commonly measured vote intention during presidential elections, but in the case of a multiparty system with stable coalitions (up to the last year under study -2014), such as the Chilean case, this implies a dramatic reduction in the number of electoral alternatives available to voters. This reduction is further accentuated for center and left-wing voters who often support single presidential candidates of the center-left coalition Concertación de Partidos por la Democracia, or its continuator from 2013, Nueva Mayoría. 
Accordingly, to demonstrate the close relationship between ideological and electoral preferences, it is more convenient to use questions that ask about vote intention for political parties in parliamentary elections so that voters' electoral preferences can be differentiated more clearly. The CEP surveys have this information during the period between 2002 and 2005, in surveys number 44 to 51 (except in survey 46). The employed question is: "Now suppose that next Sunday there were Parliamentary elections and you go to vote. The different political parties will lead different candidates to the elections. For the candidate of which of the political parties that appear in this vote, would you vote?" The response categories are: 1) Partido Demócrata Cristiano (DC), 2) Unión Demócrata Independiente (UDI), 3) Partido Comunista de Chile (PC), 4) Renovación Nacional (RN), 5) Partido Socialista de Chile (PS), 6) Partido Radical Social Demócrata (PRSD), 7) Partido por la Democracia, 8) Partido Humanista (PH), 9) No votaría porque no está inscrito, 10) No votaría y está inscrito, 11) Votaría nulo o blanco.

We code the answers of the vote intention question by the ideological position of each party. That is, the UDI and RN parties are coded as a right-wing vote; DC as a centrist vote; PS, PPD and PRSD as a center-left vote; and PC and PH as a left-wing vote. All other alternatives are coded as 'not voting'. Ideological and electoral preferences are treated as ordinal variables with values ranging from a right to a left position. The degree of association is estimated using polychoric correlations, and only include those respondents that mentioned an ideological position or a party they would vote for. We also calculate the association between those who express "No preference" in the ideological preference question and choose not to vote, or cast a null or blank vote, for which we created two dummy variables identifying each of the aforementioned alternatives. The results are shown in Figure 1a. 


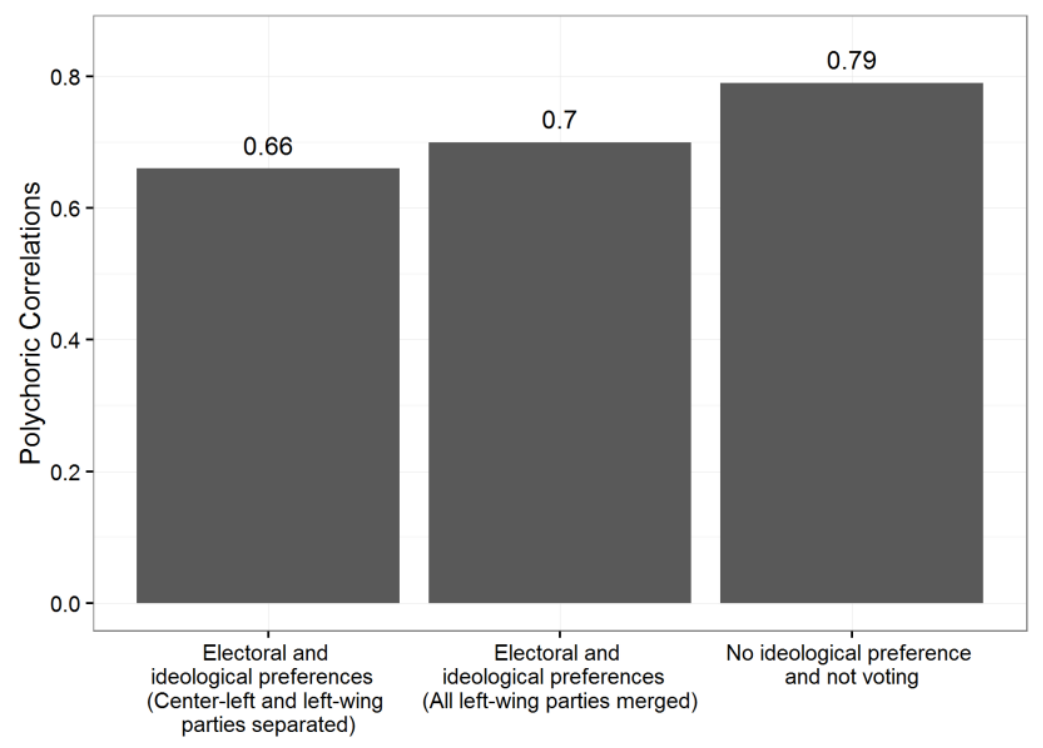

Figure 1a: Polychoric Correlations between Ideological and Electoral Preferences based on CEP surveys during period 2001-2005.

The polychoric correlation between electoral and ideological preferences is high, with rho $=0.66$. If we group the center-left vote and left-wing vote under a single category in the electoral preference question, the correlation increases up to rho $=0.70$. Likewise, the correlation between expressing no ideological preference and not voting (or casting a null/blank vote) is even higher, with rho $=0.79$.

\section{B. Validity of the Left-Right Ideological Measure}

As shown in the article, the proportion of Chileans that do not identify with an ideological position has grown considerably across the period under observation. This trend raises an important question: Do left-right preferences still influence citizens' opinions on political matters? Or has the increase in the aggregate levels of ideological apathy been accompanied with a reduction in the capacity of ideological labels to condition citizens political opinions? One simple way to respond this question is to analyze how the correlation between our 
dependent variable and other relevant political opinion variables have evolved among the population who continues to identify with ideological positions. We consider three set of variables:

a) Government approval: This variable is measured using the following question in the CEP surveys: "Regardless of your own political position, do you approve or disapprove of the way [NAME OF PRESIDENT] is leading his/her government?". This variable employs a three-point ordinal response scale: 1) Disapprove, 2) Neither approves, nor disapproves, and 3) Approves.

b) Evaluation of the National Economy: This variable is measured in CEP surveys using the following question: "Following this scale, how would you rate the current economic situation in the country?" This variable employs a five-point ordinal response scale: 1) Very bad, 2) Bad, 3) Neither good, nor bad, 4) Good, and 5) Very good.

c) Evaluation of Political Leaders: We test if respondents' left-right positions correlate with their opinions of two of the most prominent Chilean politicians of the period under study, namely, right-leaning and former president Sebastian Piñera (20102013), and left-leaning and current (and former) president Michelle Bachelet (20062009, and 2014-current). This variable is measured in CEP surveys using the following question: "Now I'm going to read a list of politicians and I want you to tell me what you think of each one of them. If you have not heard of any of the people, please tell me that you do not know them. Using the alternatives of this card, which of these phrases best describes your opinion about each person?" This variable 
employs a five-point ordinal response scale: 1) Very negative, 2) Negative, 3) Neither negative, nor positive, 4) Positive, and 5) Very positive.

The results are shown in Figure 1b. Plot A shows the polychoric correlations between government approval and ideological preferences between years 1998 and 2014. Except for years 1998 and 1999, these correlations fluctuate around 0.50 between years 2000 and 2009, which coincides with the center-left governments of Ricardo Lagos and Michelle Bachelet, and reverses sign and surpasses -0.65 during all years of the Piñera administration, and then goes back to 0.62 in 2014 when Bachelet assumes her second period. Therefore, despite the changes in the sign of the correlations these remain systematically high among those who identify with an ideological positon.

The second plot of Figure $1 \mathrm{~b}$ (Plot B), shows the evolution of the polychoric correlations between respondents' ideological positions and their evaluation of the national economy. The magnitude of the correlations is smaller than with government approval, but they do not show any sign that they are declining. In fact, the correlations increase between 1998 and 2001, then remain stable until 2010 when they change signs due to the beginning of the Piñera administration. In 2014, once Bachelet was back in office, the correlations change sign once again. 

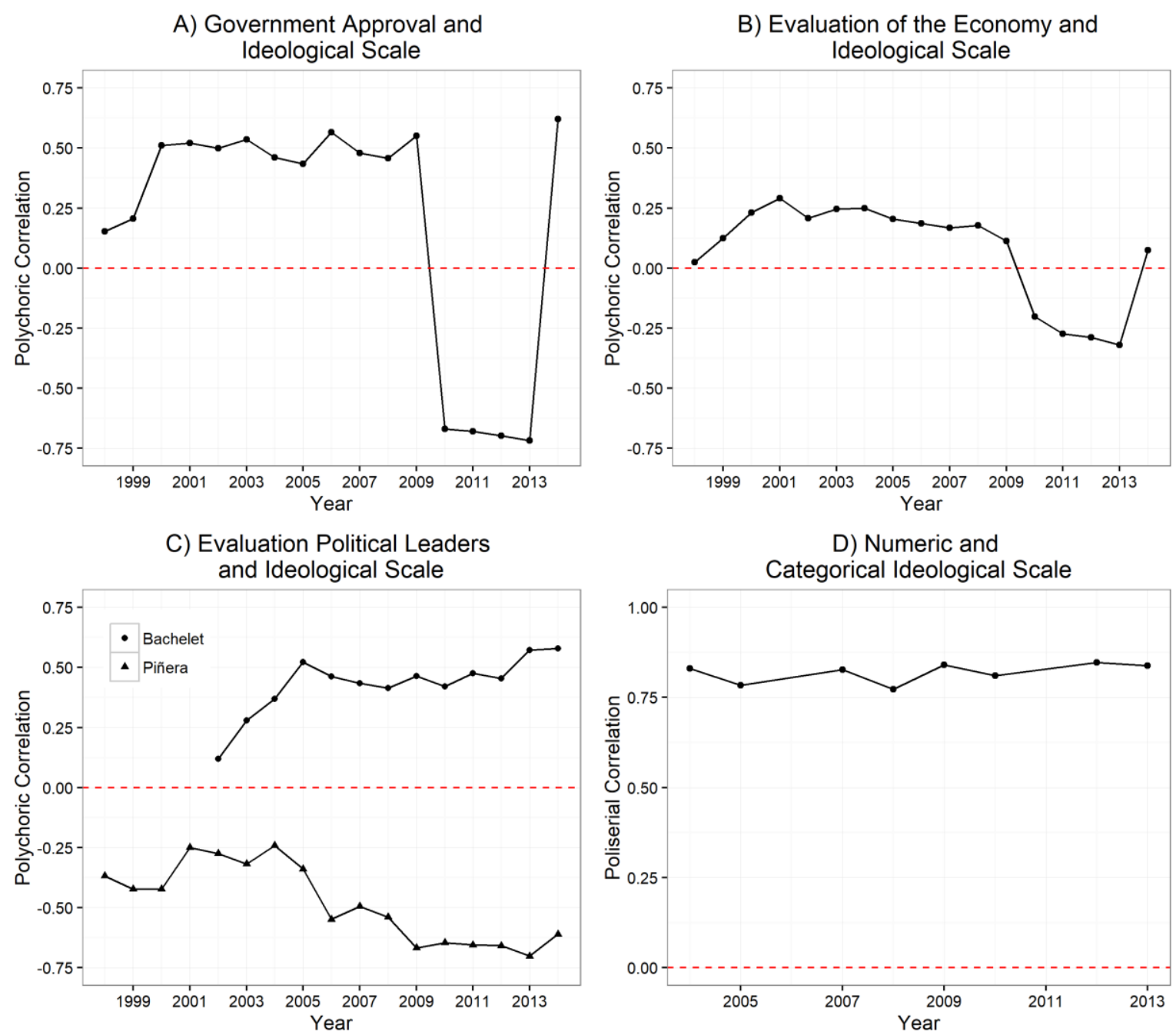

Figure 1b: Corelation between Ideological Preferences and Political Variables

Plot C provides the polychoric correlations between respondents' ideological positions and their opinions about former president Sebastian Piñera, and current (and former) president Michelle Bachelet between years 1998 and 2014 (though opinions about Bachelet were recorded since 2002, when she held the position of Minister of Defense). Once again, we do not find any evidence that the correlation has decreased in time. Quite the opposite. Since 2003 the correlations with respondents' assessments of Piñera have become stronger almost monotonically and surpassing the 0.70 level, while opinion of Bachelet has also increased systematically since 2007 . 
Finally, we carry out one last analysis with the purpose evaluating how reliable is the measure of ideological preferences we employ in the article. In other words, we assess whether our measure of ideological preferences can obtain similar results to those attained using another similar measure. To do this we exploit the fact that since 2004 some CEP surveys include, in addition to the measure we employ in the article, a 10-point numeric leftright ideological scale. The original question is: "In politics people talk about left and right. Where would you place yourself on a scale from 1 to 10 where 1 represents left and 10 represents right?". Plot D of Figure 1b shows how the polyserial correlation between the numerical and categorical ideological self-placement variables have evolved. These correlations have not only remained stable, but also are quite high. Except for two years, they rank higher than 0.80, and the annual average equals 0.82. Most importantly, and despite the rise of the proportion of the population that does not identify with an ideological position, the correlation between the two items remains equally high at the beginning of our time period than at the end. 
C. Summary Statistics

\begin{tabular}{lccccc}
\hline Variable & Obs & Mean & Std. Dev. & Min & Max \\
\hline Ideological Position & & & & & \\
Right-wing & 41040 & 0,191 & 0,393 & 0 & 1 \\
Centrist & 41040 & 0,125 & 0,331 & 0 & 1 \\
Left-wing & 41040 & 0,219 & 0,414 & 0 & 1 \\
No preference & 41040 & 0,464 & 0,499 & 0 & 1 \\
Religious Affiliation & & & & & \\
Catholic & 41040 & 0,720 & 0,449 & 0 & 1 \\
$\begin{array}{l}\text { Evangelical } \\
\text { Irreligious }\end{array}$ & 41040 & 0,167 & 0,373 & 0 & 1 \\
& 41040 & 0,113 & 0,317 & 0 & 1 \\
Frecuency of Church Attendance & 36288 & 2 & 1 & 0 & 4 \\
Year (centered at 1998) & 41040 & 9,104 & 4,350 & 0 & 16 \\
Gender (women=1) & 41040 & 0,587 & 0,492 & 0 & 1 \\
Years of Education & & & & & \\
Birth Cohort & 41040 & 10,172 & 4,543 & 0 & 25 \\
\hline
\end{tabular}

